\title{
Age and Growth of the Dusky Shark, Carcharhinus obscurus, in the Western North Pacific Ocean
}

\author{
Shoou-Jeng Joung ${ }^{1,2}$, Jun-Hsu Chen ${ }^{1}$, Chien-Pang Chin ${ }^{3,4}$, and Kwang-Ming Liu ${ }^{2,5,6, *}$ \\ ${ }^{I}$ Department of Environmental Biology and Fisheries Science, National Taiwan Ocean University, Keelung, Taiwan, R.O.C. \\ ${ }^{2}$ George Chen Shark Research Center, National Taiwan Ocean University, Keelung, Taiwan, R.O.C. \\ ${ }^{3}$ Institute of Oceanography, National Taiwan University, Taipei, Taiwan, R.O.C. \\ ${ }^{4}$ Fisheries Research Institute, Council of Agriculture, Keelung, Taiwan, R.O.C. \\ ${ }^{5}$ Center of Excellence of Oceans, National Taiwan Ocean University, Keelung, Taiwan, R.O.C. \\ ${ }^{6}$ Institute of Marine Affairs and Resource Management, National Taiwan Ocean University, Keelung, Taiwan, R.O.C.
}

Received 6 March 2014, revised 18 September 2014, accepted 15 October 2014

\begin{abstract}
Age and growth of the dusky shark, Carcharhinus obscurus, in the western North Pacific Ocean was estimated based on 434 specimens (213 females and 256 males) collected between September 2002 and November 2003 at the Nanfanao fish market, in northeastern Taiwan. Sex-specific relationships between body weight (W) and total length (TL) were estimated as follows: $\mathrm{W}=2.03 \times 10^{-6} \mathrm{TL}^{3.216}(n=209, p<0.01)$ for females and $\mathrm{W}=8.01 \times 10^{-6} \mathrm{TL}^{2.957}(n=294, p<0.01)$ for males. The relationship between TL and the vertebral centrum radius (R) for both sexes ("sexes-combined" data) was described using the following equation $\mathrm{TL}=14.74+20.31 \mathrm{R}(n=399, p<0.01)$. Growth band pairs (including translucent and opaque bands) in precaudal vertebrae were determined to form once annually, based on centrum edge analysis and verified by statistical analysis. The maximum number of growth band pairs was 29 for females and 24 for males. The Robertson growth function best fit the observed length-at-age data. Sex-specific growth equations were not significantly different; thus, the combined growth parameters for both sexes were estimated as: asymptotic length $\left(L_{\infty}\right)=369.4 \mathrm{~cm} \mathrm{TL}, b=0.912$, growth coefficient $\left(k_{R}\right)=0.126 \mathrm{yr}^{-1}$ $(n=385, p<0.01)$. Age at maturity was estimated to be 16.6 yrs for females and 15.5 yrs for males.
\end{abstract}

Key words: Dusky shark, Age and growth, Vertebral band counting, Robertson function

Citation: Joung, S. J., J. H. Chen, C. P. Chin, and K. M. Liu, 2015: Age and growth of the dusky shark, Carcharhinus obscurus, in the western North Pacific Ocean.Terr. Atmos. Ocean. Sci., 26, 153-160, doi: 10.3319/TAO.2014.10.15.01(Oc)

\section{INTRODUCTION}

The dusky shark, Carcharhinus obscurus (Lesueur, 1818), inhabits tropical and warm-temperate continental seas worldwide (Compagno 1984), including the waters of the continental shelf off the coast of northeastern Taiwan, where it is an important species for the local commercial shark fishery. According to catch statistics from the Nanfanao fish market - the largest landing port for the shark fishery in northeastern Taiwan - annual landings (whole weight) of this species fluctuated from 284 metric tons (MT) in 1990 - 193 MT in 2008, with an annual mean of 210 MT, accounting for $11.5 \%$ of the total annual shark landings in this area (excluding the blue shark, which was not included in catch statistics prior to 2008).

\footnotetext{
* Corresponding author

E-mail:kmliu@mail.ntou.edu.tw
}

Biological information about the dusky shark is extremely limited apart from descriptions of age and growth of populations in the western North Atlantic Ocean (Hoenig 1979; Natanson et al. 1995, 2014), in the southwestern Indian Ocean (Natanson and Kohler 1996), and in Australian waters (Simpfendorfer 2000; Simpfendorfer et al. 2002). The latter study used the tag-recapture technique coupled with oxytetracycline (OTC) injection and Natanson et al. (2014) used bomb radiocarbon to validate the growth of dusky sharks. However, biological information regarding this species is still lacking in the western North Pacific, especially in Taiwanese waters.

As the demand for shark fin has increased in Asian countries, dusky sharks with median sized fins have become one of the major target species. This species is listed as vulnerable (VU) on the IUCN Red List of threatened species, 
and its population is decreasing (IUCN 2014, http://www. iucnredlist.org). A proposal to include dusky sharks in the CITES Appendix II was presented at the CITES CoP15 meeting in 2010. Although this proposal was rejected the population status of this species is nonetheless of great concern to scientists and environmental groups. Hence, stock assessments and improved management of this species are urgently needed, particularly for populations in the western North Pacific. The lack of life history information hinders the implementation of fishery management measures for dusky sharks in this region. The objective of this study is therefore to provide the first detailed information regarding the age and growth of dusky sharks in the western North Pacific Ocean.

\section{MATERIALS AND METHODS}

\subsection{Source of Data}

Dusky sharks caught in the western North Pacific Ocean (Fig. 1) by Taiwanese coastal and offshore longline vessels were landed at the Nanfanao fish market in northeastern Taiwan. These sharks are caught primarily by smallscale longline fishing vessels ( $<50$ tonnages), which operate on a 7 - 14 days per trip (Liu et al. 2001). All sharks were weighed before being auctioned and processed, enabling us to obtain accurate catch statistics (numbers) and individual body (whole) weights ( $\mathrm{W}$, in $\mathrm{kg}$ ) from sales records. In total, 434 specimens collected at the Nanfanao fish market between September 2002 and November 2003 were used for age estimations (Table 1). Total length (TL, in $\mathrm{cm}$ ), fork length (FL), and pre-caudal length (PCL) measurements were made following the protocol described by Branstetter and Stiles (1987). The sex of each specimen was also recorded. Pre-caudal vertebrae, the only vertebrae available from the fish market, were removed for purposes of age determination. Linear regression was used for conversion between measurements to facilitate comparison with previous research that reported using measurements other than TL.

\subsection{Age Determination}

Intact vertebral columns from two specimens (a $131-\mathrm{cm}$ TL male and a $185-\mathrm{cm}$ TL female) were used to compare variations in band pair patterns on the vertebral centra from different locations along the specimen vertebral column. The coefficient of variation $(\mathrm{V})$ of the vertebral centrum diameter (D) was calculated for groups of ten consecutive vertebrae using the formula $V=\frac{S}{X} \times 100 \%$, where $S$ is the standard deviation of the diameters of ten consecutive vertebral centra and $\bar{X}$ is the mean diameter of ten consecutive vertebral centra. The analysis revealed that the same band pair counts ( 3 and 7 for the male and the female, respectively) were found in both the precaudal vertebrae and vertebrae located elsewhere. In addition, the smallest coefficient of variation was found for vertebrae in the precaudal region and those below the first dorsal fin. Thus, precaudal vertebrae from 185 female and 249 male dusky sharks were used for age determination.

Vertebrae were rinsed in $10 \% \mathrm{KOH}$ for 5 - 60 minutes to remove connective tissue, then rinsed with running water for $24 \mathrm{hrs}$ and air dried (Joung et al. 2004). After being soaked in ethyl alcohol and t-butyl alcohol, the vertebrae were embedded in paraffin to prevent shrinkage and deformation. The vertebral centra were then cut into two pieces along the lateral plane using an Isomet low-speed saw (Buehler, Lake Bluff, Illinois, US).

A Rigaku Industrial X-ray Apparatus was used to take radiographs of vertebral centra (Liu et al. 1998) under the condition of $0.5 \mathrm{~mA}$ and $32.5-42.5 \mathrm{KV}$ for 3 - 4 minutes, depending on the size of the vertebral centra. Growth band pairs (defined as one translucent and one opaque band) were counted without prior knowledge of the size of the specimens from which they came. The first band was assumed to be the birth mark (Fig. 2). All vertebrae were read twice by the same reader and counts were accepted only if both readings were in agreement. Following the protocol from previous studies (Chen et al. 1990; Joung et al. 2004), counts that differed by two or more band pairs were rejected. If the estimated number of band pairs differed by one, then the centra was recounted and the final count was accepted if it agreed with one of the previous counts. The radius of each centrum $(\mathrm{R})$ was measured on a line from the focus through the center of the intermedialia to the ultimate centrum margin.

\subsection{Edge Analysis}

Edge analysis (Cailliet and Goldman 2004) was used to determine the time of band formation using the monthly frequency changes in band (translucent or opaque) on the margin of vertebral centra. The periodicity obtained from the edge analysis was further verified using a model (Okamura and Semba 2009) that combines binary data with a statistical model for circular data. The most probable periodicity of band pair formation (annual, biannual, and no cycle) was selected based on a corrected Akaike's information criterion $\left(\mathrm{AIC}_{\mathrm{c}}\right.$, Akaike 1973), along with $\mathrm{AIC}_{\mathrm{c}}$ difference $\left(\Delta \mathrm{AIC}_{\mathrm{c}}\right)$ and $\mathrm{AIC}_{\mathrm{c}}$ weight $\left(w_{i}\right)$ (Burnham and Anderson 2002).

\subsection{TL-R Relation}

The relationship between TL and the centrum radius (R) was estimated using simple linear regression analysis. Because the parturition season of dusky sharks occurs in July in the western North Pacific Ocean (Chen 2004), the birth date for all specimens was set at July 1 in this study. The age of each specimen was estimated using the number of band pairs plus the time elapsed from the birth date to the day caught using the equation $t=\frac{2}{12}+n+\frac{m}{12}$, where $n$ is the number of band pairs and $m$ is the time elapsed (in 
months) between sampling date and September 1 .

\subsection{Growth Functions}

Four growth functions were used to fit the observed length-at-age data. The length at birth $\left(L_{0}\right)$ was set at $101 \mathrm{~cm}$ TL, which was the average of the largest full term embryo $(92 \mathrm{~cm})$ and the smallest free-swimming individual $(110 \mathrm{~cm}$ TL) observed (Chen 2004). The nonlinear (NLIN) procedure of the statistical package SAS V. 9.0 (SAS Institute Inc. 2008, Cary, North Carolina, USA) was used to estimate the parameters of each function. The four growth functions used were as follows:

(1) von Bertalanffy growth function (VBGF, Beverton 1954): $L_{t}=L_{\infty}\left[1-e^{-k\left(t-t_{0}\right)}\right]$, where $L_{t}$ is the length at age $t, L_{\infty}$ is the asymptotic length, $k$ is the growth coefficient, $t$ is the age (year from birth), and $t_{0}$ is the theoretical age at length 0 .

(2) Two-parameter VBGF (Fabens 1965): $L_{t}=L_{\infty}-\left(L_{\infty}-L_{0}\right) e^{-k t}$, where $L_{0}$ is the length at birth.

(3) Robertson (Logistic) growth function (Robertson 1923): $L_{t}=\frac{L_{\infty}}{1+e^{\left(b-k_{k} t\right)}}$, where $b$ and $k_{R}$ represent the parameter to be estimated and the growth coefficient of the Robertson function, respectively.

(4) Gompertz growth function (Gompertz 1825): $L_{t}=L_{\infty} e^{-e^{(c-k C))}}$ , where $k_{G}$ is the growth coefficient of the Gompertz function and $c$ is the parameter to be estimated.

The goodness of fit of the four growth functions was compared based on the corrected $\mathrm{AIC}_{\mathrm{c}}, \Delta \mathrm{AIC}_{\mathrm{c}}$, and $w_{i}$ (Burnham and Anderson 2002). AIC $_{\mathrm{c}}$ was expressed as: $\mathrm{AIC}_{\mathrm{c}}=\mathrm{AIC}+\frac{2 K(K+1)}{n-K-1}, \mathrm{AIC}=n \times \ln (\mathrm{MSE})+2 K($ Akaike 1973), where $n$ is the total sample size, MSE is the mean square of residuals and $K$ is the number of parameters estimated in the growth function. The $\Delta \mathrm{AIC}_{\mathrm{c}}$ in each model was calculated as the difference in $\mathrm{AIC}_{c, i}$ and the lowest observed $\mathrm{AIC}_{\mathrm{c}}$ value $\left(\mathrm{AIC}_{\mathrm{cmin}}\right)$. Models with $\triangle \mathrm{AIC}_{\mathrm{c}}$ values lower than 2 have good support, while those with values greater than 10 have no support. The $w_{i}$ is expressed as a percentage and is useful when there are only minor differences in AIC values among the growth functions (Burnham and Anderson 2002). The $w_{i}$ with higher values indicating a better fit can be expressed as follows:

$w_{i}=\frac{\exp \left(-0.5 \Delta_{i}\right)}{\sum_{m=1}^{4} \exp \left(-0.5 \Delta_{m}\right)}$

where $m$ is the number of growth functions being analyzed. A maximum likelihood ratio test (Kimura 1980) was used to examine the difference in growth between the sexes.

The age at maturity was estimated by substituting the $50 \%$ size at maturity estimate (Chen 2004) into the best growth function being selected. The relationship between $\mathrm{W}$ and TL was also determined for both males and females. An analysis of covariance (ANCOVA) (Zar 2010) was used to compare the meristic relationships between the sexes, while the maximum likelihood ratio test (Kimura 1980) was used to compare the weight-length relationship and growth functions between the sexes.

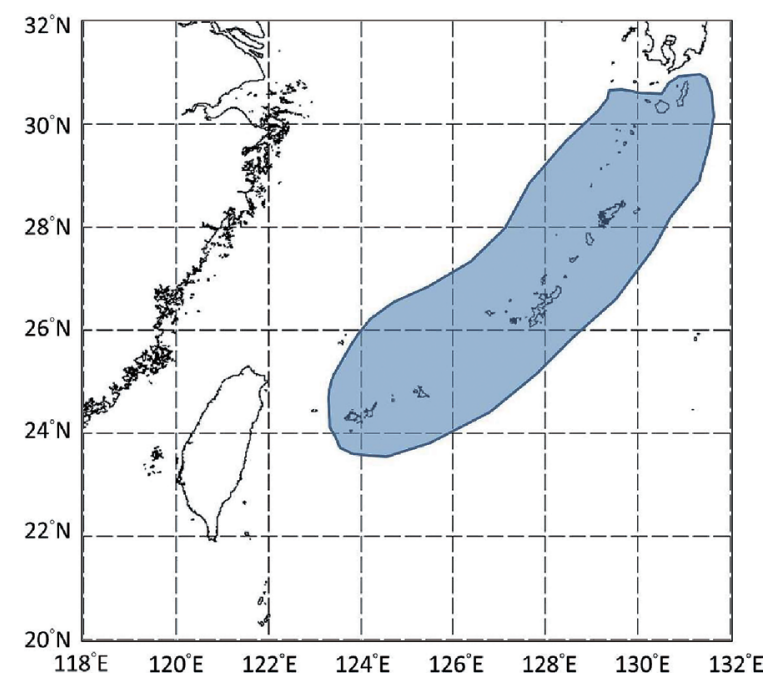

Fig. 1. Sampling area of dusky sharks in the western North Pacific Ocean.

Table 1. Comparison of goodness-of-fit among different periodicities of vertebral band pair formation for dusky sharks.

\begin{tabular}{cccc}
\hline Periodicity of band pair formation & $\mathbf{A I C}_{\mathbf{c}}$ & $\boldsymbol{\Delta} \mathbf{A I C}_{\mathbf{c}}$ & $\boldsymbol{w}_{\boldsymbol{i}}$ \\
\hline No cycle & 480.53 & 46.96 & 0 \\
Annual cycle & 433.57 & 0 & 0.997 \\
Biannual cycle & 444.88 & 11.31 & 0.003 \\
\hline
\end{tabular}

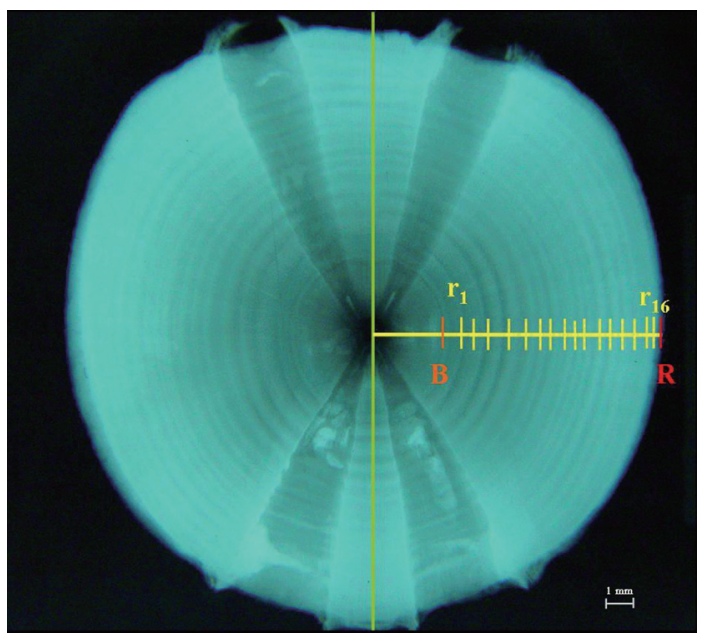

Fig. 2. The X-ray radiograph of a laterally cut vertebral centrum showing growth band pairs on vertebral centrum of a female dusky shark $(285 \mathrm{~cm} \mathrm{TL})$; B: birth mark, R: centrum radius. 


\section{RESULTS}

\subsection{Meristic Relationships}

There were no significant differences between males and females in terms of meristic relationships (ANCOVA, $p>0.05)$. Thus, the sexes-combined relationships between TL, FL, and PCL were estimated as follows:

$\mathrm{FL}=-0.57+0.82 \mathrm{TL}\left(r^{2}=0.99, n=670, p<0.01\right)$

$\mathrm{PCL}=-3.73+0.76 \mathrm{TL}\left(r^{2}=0.99, n=670, p<0.01\right)$

\subsection{TL-R and W-TL Relationships}

Linear relationships between TL and R were found to be significant for both sexes, and no significant difference was detected between the sexes. Thus, the relationship between TL and R for both sexes-combined was described as follows:

$\mathrm{TL}=14.74+20.31 \mathrm{R}\left(r^{2}=0.91, n=399, p<0.01\right)$

A significant difference between the sexes was found for the W-TL relationship. Thus, the sex-specific relationships between $\mathrm{W}$ and TL were described as follows:

$\mathrm{W}=2.03 \times 10^{-6} \mathrm{TL}^{3.216}$ for females

$\left(r^{2}=0.98, n=209, p<0.01\right)$

$\mathrm{W}=8.01 \times 10^{-6} \mathrm{TL}^{2.957}$ for males

$\left(r^{2}=0.98, n=294, p<0.01\right)$

The sexes-combined proportion of bands at the vertebral centra edge indicated that the proportion of opaque bands began to increase in March, peaked in September and decreased thereafter, suggesting that an opaque band forms once a year between September and October (Fig. 3). Okamura and Semba's (2009) analysis also indicated that annual band pair formation was most probable, due to that scenario having the smallest $\mathrm{AIC}_{\mathrm{c}}$ and the highest $w_{i}$ (Table 1), with a good fit between predicted probability and observations (Fig. 3). There was no support for the biannual and no cycle per year scenarios, because $\Delta \mathrm{AIC}_{\mathrm{c}}$ was greater than 10 and because only very low values of $w_{i}$ were found (Table 1).

To determine if the birth band was correctly assumed on the vertebral centra of the dusky sharks, the radius length of the birth mark was substituted in the TL-R equation. The theoretical length of the birth mark at the time of formation was $111.9 \mathrm{~cm}$, which was larger than the size at birth of $101 \mathrm{~cm}$. No growth band was observed on the vertebrae of two full-term embryos collected in the parturition season, suggesting that the birth mark was formed after parturition. Two opaque bands (the birth mark and one newly formed) were found on the two smallest free-swimming individuals collected in late February. If the birth date and band formation date were assumed to be July 1 and September 1 , respectively, then the birth mark and the first band after birth were formed 2 and 14 months after birth, respectively. These estimates indicated that our birth mark assumption in the vertebral centra was correct.

In total, 18 (4.1\%) vertebrae were discarded due to failure in processing and another $29(6.7 \%)$ were discarded due to inconsistencies in band pair readings. Maximum numbers of band pairs counted were 29 for females and 24 for males, based on 387 vertebrae.

\subsection{Growth Parameters}

Estimated parameters for the four growth functions are shown in Table 2. The growth function between the sexes was not significantly different at the $5 \%$ level, based on the maximum likelihood ratio test. The Robertson growth function had the smallest $\mathrm{AIC}_{\mathrm{c}}$ (Table 3 ), but the Gompertz function was supported equally well $\left(\Delta \mathrm{AIC}_{\mathrm{c}}<2\right)$. However, the highest $w_{i}$ indicated that the Robertson growth function is the best model for fitting the observed length-at-age data for dusky sharks. The parameters of the sexes-combined Robertson function for dusky sharks were estimated as follows: $L_{\infty}=369.4 \mathrm{~cm} \mathrm{TL}, b=0.912, k_{R}=0.126 \mathrm{yr}^{-1}(n=385$, $p<0.01$ ) (Fig. 4).

Chen (2004) reported that the 50\% sizes at maturity of dusky sharks in the waters of northeastern Taiwan were 281 and $273 \mathrm{~cm}$ TL for females and males, respectively, based on maturity ogives. These values correspond to $16.4 \mathrm{yrs}$ for females and $15.5 \mathrm{yrs}$ for males, based on the Robertson growth equation.

\section{DISCUSSION}

The specimens used in this study encompass a wide range of sizes for this species (110 - $364 \mathrm{~cm} \mathrm{TL})$, but individuals smaller than $110 \mathrm{~cm}$ TL and larger than size at birth (101 cm TL, Chen 2004) were rarely captured by the longline fishery, possibly because the pupping ground was not fished. Size-specific gear selectivity may be another potential factor. The lack of very young specimens may result in an overestimate of $L_{\infty}$, but our estimate (369.4 cm TL) using the Robertson growth function is only slightly larger than the maximum observed size ( $364 \mathrm{~cm} \mathrm{TL}$ ) and is thought to be biologically realistic. To improve the accuracy of parameter estimation, future work should focus on the collection of very young specimens.

Cailliet et al. (2006) and Goldman et al. (2012) noted that both marginal increment analysis (MIA) and edge analysis can be used to provide valuable corroborative evidence 


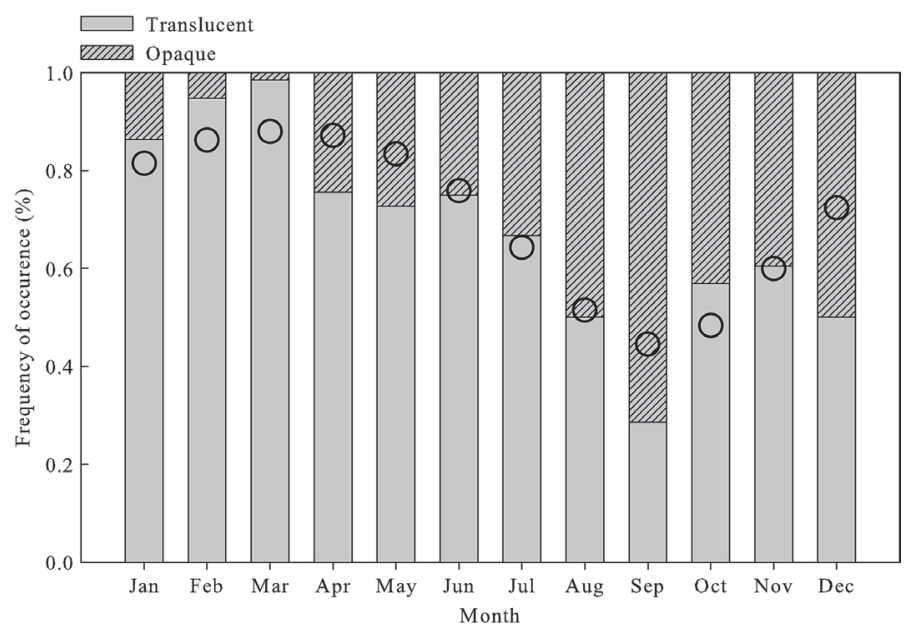

Fig. 3. Monthly frequency changes in band edge on vertebral centrum for dusky sharks. Numbers indicate sample size, O: predicted probability of annual cycle from Okamura and Semba's method (2009).

Table 2. Estimates of growth parameters and goodness of fit for four growth functions fitted to observed size-at-age data of dusky shark.

\begin{tabular}{|c|c|c|c|c|c|c|c|c|}
\hline \multicolumn{9}{|c|}{ Sexes-combined } \\
\hline \multirow{2}{*}{ Growth model } & \multicolumn{5}{|c|}{ Parameters } & \multirow{2}{*}{$\mathbf{A I C}_{\mathrm{c}}$} & \multirow{2}{*}{$\Delta \mathrm{AIC}_{\mathrm{c}}$} & \multirow{2}{*}{$w_{i}$} \\
\hline & $L_{\infty}(\mathrm{SE})$ & $k(\mathrm{SE})$ & $k_{R}(\mathrm{SE})$ & $k_{G}(\mathrm{SE})$ & $t_{0}(\mathrm{SE})$ & & & \\
\hline VBGF & $456.0(30.0)$ & $0.046(0.007)$ & - & - & $-4.23(0.742)$ & 2381.0 & 3 & 0.11 \\
\hline VBGF with $L_{0}$ & $562.8(39.9)$ & $0.029(0.003)$ & - & - & - & 2391.0 & 13 & 0.00 \\
\hline Robertson & $369.4(9.93)$ & - & $0.126(0.008)$ & - & - & 2378.0 & 0 & 0.51 \\
\hline Gompertz & 394.7 (14.4) & - & - & $0.086(0.007)$ & - & 2378.6 & 0.6 & 0.38 \\
\hline
\end{tabular}

Table 3. Growth parameters of dusky sharks derived from different studies.

\begin{tabular}{|c|c|c|c|c|c|c|c|c|c|c|}
\hline Region & Method & Sex & Model & $L_{\infty}(\mathbf{c m} \mathbf{F L})$ & $k / k_{R} / k_{g}\left(\right.$ year $\left.^{-1}\right)$ & $t_{0}($ year $)$ & $n$ & $t_{\text {mat }}$ & Size range (cm FL) & Source \\
\hline \multirow[t]{6}{*}{ NW Pacific } & VA & M & Robertson & 324.6 & 0.125 & & 200 & 15.5 & $90-290$ & This study \\
\hline & VA & $\mathrm{F}$ & Robertson & 324.6 & 0.126 & & 165 & 16.4 & $91-298$ & This study \\
\hline & VA & $\mathrm{C}$ & Robertson & 324.5 & 0.126 & & 385 & & $90-298$ & This study \\
\hline & VA & M & VBGF & 387.5 & 0.043 & -4.45 & 220 & 15.5 & $90-290$ & This study \\
\hline & VA & $\mathrm{F}$ & VBGF & 368.6 & 0.046 & -4.23 & 165 & 16.4 & $91-298$ & This study \\
\hline & VA & $\mathrm{C}$ & VBGF & 373.4 & 0.046 & -4.23 & 385 & & $90-298$ & This study \\
\hline \multirow[t]{3}{*}{ SE Indian } & VA & M & VBGF2 & 336.5 & 0.045 & - & & $20-23$ & & Simpfendorfer et al. (2002) \\
\hline & VA & $\mathrm{F}$ & VBGF2 & 354.4 & 0.043 & - & & $17-22$ & & Simpfendorfer et al. (2002) \\
\hline & VA & $\mathrm{C}$ & VBGF2 & 351 & 0.043 & - & 305 & & 63 (neonate) - 282 & Simpfendorfer et al. (2002) \\
\hline SW Indian & VA & $\mathrm{C}$ & VBGF & 334 & 0.047 & -5.18 & 42 & & & Natanson and Kohler (1996) \\
\hline \multirow[t]{3}{*}{ NW Atlantic } & VA & M & VBGF & 373 & 0.038 & -6.28 & 47 & 19 & & Natanson et al. (1995) \\
\hline & VA & $\mathrm{F}$ & VBGF & 349 & 0.039 & -7.04 & 67 & 21 & & Natanson et al. (1995) \\
\hline & VA & $\mathrm{C}$ & VBGF & 352 & 0.040 & -6.43 & 120 & & 73 (neonate) - 296 & Natanson et al. (1995) \\
\hline \multirow[t]{3}{*}{ NW Atlantic } & $\mathrm{LF}$ & M & VBGF & 293 & 0.049 & -5.99 & 133 & 19 & & Natanson et al. (1995) \\
\hline & $\mathrm{LF}$ & $\mathrm{F}$ & VBGF & 392 & 0.040 & -5.34 & 208 & 21 & & Natanson et al. (1995) \\
\hline & $\mathrm{LF}$ & $\mathrm{C}$ & VBGF & 296 & 0.062 & -4.68 & 350 & & 73 (neonate) - 296 & Natanson et al. (1995) \\
\hline
\end{tabular}

Note: VA: Vertebral analysis, LF: length-frequency analysis, VBGF2: two-parameter VBGF, $t_{\text {mat }}$ : age at maturity, Logistic is the same as Robertson function. 
Table 3. (Continued)

\begin{tabular}{|c|c|c|c|c|c|c|c|c|c|c|}
\hline Region & Method & Sex & Model & $L_{\infty}(\mathrm{cm} \mathrm{FL})$ & $k / k_{R} / k_{g}\left(\right.$ year $\left.^{-1}\right)$ & $t_{0}$ (year) & $n$ & $t_{m a t}$ & Size range $(\mathrm{cm}$ FL) & Source \\
\hline \multirow[t]{3}{*}{ NW Atlantic } & VA & M & Logistic & 284.4 & 0.139 & & 113 & & $74-276$ & Natanson et al. (2014) \\
\hline & VA & F & Gompertz & 319.4 & 0.078 & & 138 & & $76-300$ & Natanson et al. (2014) \\
\hline & VA & $\mathrm{C}$ & Logistic & 261.5 & 0.148 & & 251 & & $74-300$ & Natanson et al. (2014) \\
\hline \multirow[t]{2}{*}{ NW Atlantic } & VA & $\mathrm{C}$ & VBGF & 385 & 0.034 & -5.99 & 22 & & & Hoenig (1979) \\
\hline & VA & F & VBGF & 732 & 0.014 & -6.70 & 13 & & & Hoenig (1979) \\
\hline
\end{tabular}

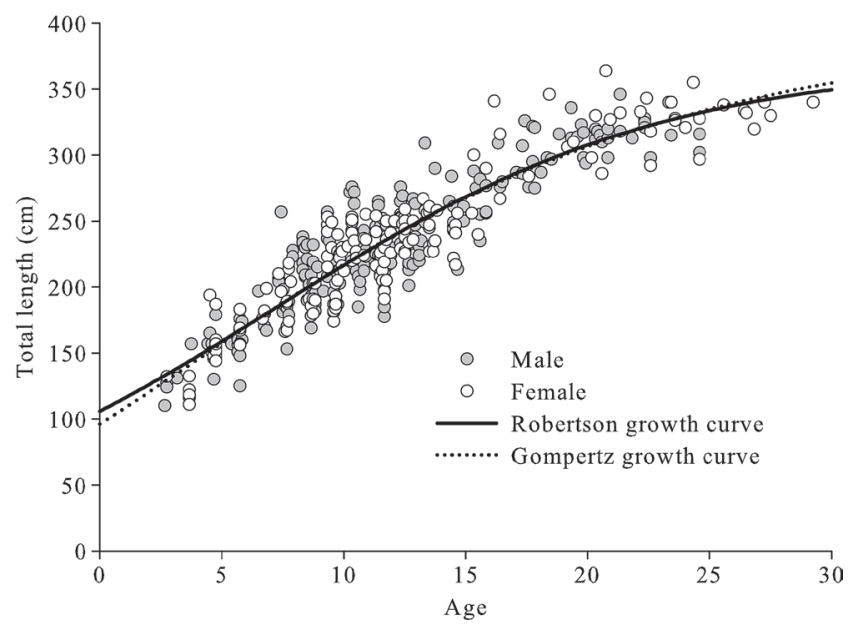

Fig. 4. The sexes-combined Robertson (black solid line), and Gompertz (black dotted line) growth curves for dusky sharks; O: females, o: males.

for the periodicity of band formation. Because of uncertainty in the radii of the ultimate and penultimate bands measurements, we used edge analysis alone to verify the periodicity of band pair formation in this study. Our analysis suggested that a single growth band pair was formed annually. The results derived from the statistical model (Okamura and Semba 2009) supported our results. The annual band pair deposition scenario received the highest support $\left(w_{i}=0.997\right)$, while the biannual and no cycle scenarios were rejected because of their low $w_{i}$ values (Table 2). Annual band pair deposition was reported by other researchers studying dusky sharks in other locations, including the western North Atlantic Ocean (Natanson et al. 1995) and the southwestern Indian Ocean (Natanson and Kohler 1996). Simpfendorfer (2000) used a tag-recapture approach to calculate estimates of the growth rate of juvenile dusky sharks, while Simpfendorfer et al. (2002) used tetracycline labeling for individuals aged $5 \mathrm{yrs}$ or less to calculate estimates of the age and growth of dusky sharks in Australian waters. More recently, Natanson et al. (2014), used bomb radiocarbon dating in reporting the annual deposition of band pairs in dusky sharks as old as $11 \mathrm{yrs}$ in the northwestern Atlantic Ocean. The authors concluded that the vertebral band counting method underestimated the true age of dusky sharks older than 11 yrs of age and sug- gested that the decline of band pair deposition beyond the age of 11 may be related to somatic growth or the onset of maturity. Whether our estimates underestimated the true age of dusky sharks in the western North Pacific Ocean needs further investigation.

Edge analysis indicated that the opaque band on vertebral centrum was formed in September to October (fall). However, Simpfendorfer et al. (2002) concluded that the opaque band in dusky sharks in Australian waters was formed in December or January (summer). Differences in environmental conditions and food availability between the two sampling locations may account for the disparity in band deposition time observed in the two studies. Although several possible explanations for band formation have been proposed, the average water temperatures at the depths that dusky sharks inhabit $(75-125 \mathrm{~m})$ in the northern Taiwan waters are very stable year round $\left(20.17-21.02^{\circ} \mathrm{C}\right)$ (Ocean Data Bank 2011). This indicates that band formation in dusky sharks in the western North Pacific may not be closely linked to changes in water temperature.

The $L_{\infty}$ of the sexes-combined Robertson growth function was only slightly larger than the maximum observed size of $364 \mathrm{~cm}$ TL for females and $354 \mathrm{~cm}$ TL for males, suggesting that our estimation is biologically realistic. Likewise, our estimates for the Robertson function parameters were comparable to those derived by Natanson et al. (2014) from validated ages using the same growth function, while our estimates for the VBGF parameters (although not the best fitting model) were also comparable to those from other studies that used VBGF (Table 3). The growth curves we derived from both the VBGF and Robertson functions were similar to those from other studies on dusky sharks up to 10 yrs of age, but the discrepancy increased with age thereafter (Fig. 5). Our study predicted larger sizes for sharks older than 10 yrs, suggesting that dusky sharks in the western North Pacific grow more rapidly than dusky sharks in the Atlantic and Indian oceans. This may be due to the difference in ocean water temperature, as temperature plays an important role in determining the growth rates of sharks (Simpfendorfer et al. 2002). The specimens used in this study were primarily from subtropical waters $\left(25-30^{\circ} \mathrm{N}\right)$, whereas specimens examined by Natanson et al. (1995), Natanson and Kohler (1996), Simpferdorfer et al. (2002), 


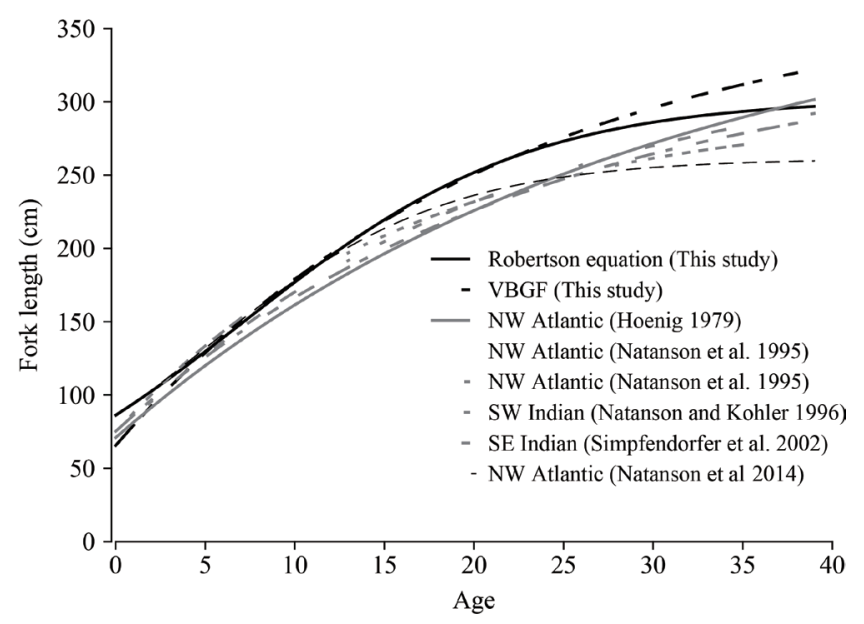

Fig. 5. Comparison of the growth curves of dusky sharks from different regions. VBGF: Hoenig (1979), Natanson et al. (1995), Natanson and Kohler (1996), this study; two-parameter VBGF: Simpfendorf et al. (2002); Robertson (logistic): Natanson et al. (2014), and this study.

and Natanson et al. (2014) were primarily collected from more temperate waters $\left(35-45^{\circ} \mathrm{N}\right.$ or $\left.{ }^{\circ} \mathrm{S}\right)$.

Because this study was based on a large sample size and a broad range of specimen sizes ( $n=385,110-364 \mathrm{~cm} \mathrm{TL})$, we believe that our results accurately depict the age and growth of dusky sharks in the western North Pacific Ocean. In addition, our samples were collected over a consecutive 15-month period, suggesting that the results derived from this study are robust. Although no stock assessment of dusky sharks in the western North Pacific has been conducted, the characteristics of slow growth $\left(k_{R}=0.126 \mathrm{yr}^{-1}\right)$, late maturity (16.6 and 15.5 yrs for females and males, respectively), and few offspring (11/litter) (Chen 2004) render this population vulnerable to overfishing. Rigorous monitoring of dusky shark size composition and a detailed stock assessment is needed to ensure sustainable exploitation of this species.

Acknowledgements We thank Dr. G. M. Cailliet and one anonymous reviewer for their constructive comments and suggestions, which greatly improved the quality of this manuscript. Financial support for this study was provided by the National Science Council, R.O.C., Grants NSC 972313-B-019-032 and NSC 98-2313-B-019-048.

\section{REFERENCES}

Akaike, H., 1973: Information theory and an extension of the maximum likelihood principle. In: Petrov, B. N. and F. Caski (Eds.), Proceeding of the Second International Symposium on Information Theory, Akademiai Kiado, Budapest, 267-281.

Beverton, R. J. H., 1954: Notes on the use of theoretical models in the study of the dynamics of exploited fish populations. Miscellaneous contributions (U.S. Fishery
Laboratory), No. 2, Beaufort, North Carolina, 181 pp.

Branstetter, S. and R. Stiles, 1987: Age and growth estimates of the bull shark, Carcharhinus leucas, from the northern Gulf of Mexico. Environ. Biol. Fish., 20, 169181, doi: 10.1007/BF00004952. [Link]

Burnham, K. P. and D. R. Anderson, 2002: Model Selection and Multimodel Inference: A Practical InformationTheoretic Approach, Springer New York, 488 pp, doi: 10.1007/b97636. [Link]

Cailliet, G. M. and K. J. Goldman, 2004: Age determination and validation in chondrichthyan fishes. In: Carrier, J. C., J. A. Musick, M. R. Heithaus (Eds.), Biology of Sharks and Their Relatives, CRC Press, Boca Raton, New York, 399-447, doi: 10.1201/9780203491317. pt3. [Link]

Cailliet, G. M., W. D. Smith, H. F. Mollet, and K. J. Goldman, 2006: Age and growth studies of chondrichthyan fishes: The need for consistency in terminology, verification, validation, and growth function fitting. Environ. Biol. Fish., 77, 211-228, doi: 10.1007/s10641006-9105-5 [Link]

Chen, C. T., T. C. Leu, S. J. Joung, and N. C. H. Lo, 1990: Age and growth of the scalloped hammerhead, Sphyrna lewini, in northeastern Taiwan waters. Pac. Sci., 44, 156-170.

Chen, J. H., 2004: Fishery biology of the dusky shark, Carcharhinus obscurus in the Northwest Pacific, National Taiwan Ocean University, 120 pp.

Compagno, L. J. V., 1984: FAO Species Catalogue, Vol. 4. Sharks of the World, An Annotated and Illustrated Catalogue of Shark Species Known to Date, Part 2 Carcharhiniformes United Nations Development Programme, Food and Agriculture Organization of the United Nations, 251-655.

Fabens, A. J., 1965: Properties and fitting of the von Bertalanffy growth curve. Growth, 29, 265-289.

Goldman, K. J., G. M. Cailliet, A. H. Andrews, and L. J. Natanson, 2012: Assessing the age and growth of chondrichthyan fishes. In: Carrier, J. C., J. A. Musick, and M. R. Heithaus (Eds.), Biology of Sharks and Their Relatives, $2^{\text {nd }}$ edition, CRC Press, Boca Raton, New York, 423-451, doi: 10.1201/b11867-18. [Link]

Gompertz, B., 1825: On the nature of the function expressive of the law of human mortality, and on a new mode of determining the value of life contingencies. Phil. Trans. Roy. Soc. Lond., 115, 513-583, doi: 10.1098/ rstl.1825.0026. [Link]

Hoenig, J. M., 1979: Growth rates of large sharks determined by vertebral rings. Ph.D. Thesis, University of Rhode Island, Kingston.

Joung, S. J., Y. Y. Liao, and C. T. Chen, 2004: Age and growth of sandbar shark, Carcharhinus plumbeus, in northeastern Taiwan waters. Fish. Res., 70, 83-96, doi: 10.1016/j.fishres.2004.06.018. [Link] 
Kimura, D. K., 1980: Likelihood methods for the von Bertalanffy growth curve. Fish. Bull., 77, 765-776.

Liu, K. M., P. J. Chiang, and C. T. Chen, 1998: Age and growth estimates of the bigeye thresher shark, Alopias superciliosus, in northeastern Taiwan waters. Fish. Bull., 96, 482-491.

Liu, K. M., C. T. Chen, and S. J. Joung, 2001: A study of shark resources in the waters off Taiwan. In: Liao, I. C. and J. Baker (Eds.), A Study of Shark Resources in the Waters off Taiwan, Proc. Joint Taiwan-Australia Aquacul, Fish. Resour. Manag. Forum, 249-256.

Natanson, L. J. and N. E. Kohler, 1996: A preliminary estimate of age and growth of the dusky shark Carcharhinus obscurus from the South-West Indian Ocean, with comparisons to the western North Atlantic population. S. Afr. J. Mar. Sci., 17, 217-224, doi: 10.2989/025776196784158572. [Link]

Natanson, L. J., J. G. Casey, and N. E. Kohler, 1995: Age and growth estimates of the dusky shark, Carcharhinus obscurus, in the western North Atlantic Ocean. Fish. Bull., 93, 116-126.

Natanson, L. J., B. J. Gervelis, M. V. Winton, L. L. Hamady, S. J. B. Gulak, and J. K. Carlson, 2014: Validated age and growth estimates for Carcharhinus obscurus in the northwestern Atlantic Ocean, with pre- and post man- agement growth comparisons. Environ. Biol. Fish., 97, 881-896, doi: 10.1007/s10641-013-0189-4. [Link]

Ocean Data Bank, 2011: Ocean Data Bank of the Ministry of Science and Technology, Republic of China. Available at http://www.odb.ntu.edu.tw/.

Okamura, H. and Y. Semba, 2009: A novel statistical method for validating the periodicity of vertebral growth band formation in elasmobranch fishes. Can.J. Fish. Aquat. Sci., 66, 771-780, doi: 10.1139/F09-039. [Link]

Robertson, T. B., 1923: The chemical basis of growth and senescence. In: Loeb, J., T. H. Morgan, and W. J. V. Osterhout (Eds.), Monographs on Experimental Biology, Philadelphia and London, J. B. Lippincott Company, $389 \mathrm{pp}$.

Simpfendorfer, C. A., 2000: Growth rates of juvenile dusky sharks, Carcharhinus obscurus (Lesueur, 1818), from southwestern Australia estimated from tag-recapture data. Fish. Bull., 98, 811-822.

Simpfendorfer, C. A., R. B. McAuley, J. Chidlow, and P. Unsworth, 2002: Validated age and growth of the dusky shark, Carcharhinus obscurus, from Western Australian waters. Mar. Freshw. Res., 53, 567-573, doi: 10.1071/MF01131. [Link]

Zar, J. H., 2010: Biostatistical Analysis, $5^{\text {th }}$ edition, Prentice Hall, 944 pp. 